\title{
Evidence for Reduced Charge Recombination in Carbon Nanotube/Perovskite-based Active Layers
}

Monojit Bag ${ }^{1,3}$, Lawrence A. Renna ${ }^{1}$, Seung Pyo Jeong ${ }^{1}, \mathrm{Xu} \mathrm{Han}^{2}$, Christie L. Cutting ${ }^{1}$, Dimitrios Maroudas ${ }^{2}$, and D. Venkataraman ${ }^{*} \dagger$

${ }^{1}$ Department of Chemistry, University of Massachusetts Amherst, 710 North Pleasant Street, Amherst MA, 01003 United States

${ }^{2}$ Department of Chemical Engineering, University of Massachusetts Amherst, 686 North Pleasant Street, Amherst MA, 01003 United States

${ }^{3}$ Present Address: Department of Physics, Indian Institute of Technology Roorkee, Roorkee 247667, Uttarakhand, India

\section{Corresponding Author}

*E-mail:dv@chem.umass.edu (D. Venkataraman)

\begin{abstract}
Using impedance spectroscopy and computation, we show that incorporation of multiwall carbon nanotubes (MWCNTs) in the bulk of the active layer of perovskite-based solar cells reduces charge recombination and increases the open circuit voltage. An $\sim 87 \%$ reduction in recombination was achieved when MWCNTs were introduced in the planar-heterostructure perovskite solar cell containing mixed counterions. The open circuit voltage $\left(\mathrm{V}_{\mathrm{oc}}\right)$ of perovskite/MWCNTs devices was increased by $70 \mathrm{mV}$, while the short circuit current density $\left(\mathrm{J}_{\mathrm{sc}}\right)$ and fill factor $(\mathrm{FF})$ remained unchanged.
\end{abstract}

\section{KEYWORDS}

Perovskite Solar Cells, Carbon Nanotubes, Electrochemical Impedance Spectroscopy, Charge Recombination, Hexabenzocoronene.

\section{INTRODUCTION}

Lead halide-based perovskite solar cells [1-9] have garnered widespread attention because of their high efficiency $[10,11]$ and low-temperature solution processing [12]. Over the past few years there have been numerous reports on perovskite solar cells, especially on materials processing [4,13] and interface engineering $[10,14]$, to enhance device efficiency. A key feature of lead tri-halide-based perovskites is that they are ambipolar charge transporters [5, 15]. Upon photo-illumination, photo-generated carriers, i.e., electrons and holes, get transported through the same active layer. Thus, although the mobilities of the charge carriers are high in the perovskite layer, inefficient charge

(C) 2016. This manuscript version is made available under the Elsevier user license http://www.elsevier.com/open-access/userlicense/1.0/ 
extraction out of the active layer leads to charge recombination $[16,17]$ in the bulk, which lowers the open circuit voltage $\left(\mathrm{V}_{\mathrm{oc}}\right)$. Theoretical calculations predict that the open circuit voltage can be increased by $60 \mathrm{mV}$ if the charge recombination losses are reduced by an order of magnitude [18]. Thus, perovskite solar cells require either an electron- or a hole-transporting layer or both for selective charge extraction at the perovskite/electrode interfaces. [19] In a conventional device, a compact or a nanostructured/mesoporous $\mathrm{TiO}_{2}$ layer is used as the electron transporting material (ETM), which extracts the electrons from the perovskite layer and reduces the charge recombination [16, 20, 21]. 2,2',7,7'-tetrakis(N,N-di-p-methoxyphenylamine)-9,9'-spirobifluorene (spiro-OMeTAD) is commonly used as the hole transporting material (HTM) [22]. In an inverted device architecture, a thin layer of poly(3,4-ethylenedioxythiophene) polystyrene sulfonate (PEDOT:PSS) is placed between the ITO electrode and the active layers to extract the holes. A [6,6]-phenyl- $\mathrm{C}_{61}$-butyric acid methyl ester (PCBM) layer is placed between the metal electrode and the perovskite layer to extract the electrons $[11,12]$. Except for mesoporous $\mathrm{TiO}_{2}$, all other methods focus on the extraction of charges at the interface and not in the bulk. Moreover, the electron and hole mobilities in PCBM and PEDOT:PSS, respectively, are very low compared to those in the perovskite active layer. Modifications to PCBM [23] or PEDOT:PSS layers [24] are necessary to increase the electron or hole extraction rate. Nanostructured carbon [25], including CNTs and graphene based systems, has been used for a variety of energy applications particularly transparent electrodes and charge transport layers [26]. CNTs have been used in composite materials as electrodes for perovskite devices [27, 28]. Also, CNTs have been incorporated at the perovskiteelectrode interface [29-34], which helps with hole extraction at the interface. In principle, one can extend this concept to extract holes from the bulk also if CNTs are incorporated with the active layer. However, this has been a challenge because in has been difficult to obtain stable CNT dispersions in solvents that are compatible with perovskite active layer fabrication. Herein, we show the facile incorporation of MWCNTs in the bulk of the perovskite layer and the reduction in recombination losses by $87 \%$. We also demonstrate that the introduction of MWCNTs in the bulk of the perovskite layer reduces the charge accumulation at the perovskite/ PEDOT:PSS interface and leads to improved $\mathrm{V}_{\mathrm{oc}}$ and thus higher power conversion efficiency (PCE).

\section{MATERIALS AND METHODS}

Stable dispersions of MWCNTs were prepared in DMF as shown in Figure 1. For this study, we used MWCNTs that have outer diameters of 40-60 nm and lengths of 1-2 $\mu \mathrm{m}$. First, MWCNTs were added to DMF $\left(0.1 \mathrm{mg} \cdot \mathrm{mL}^{-1}\right)$ 
along with poly(methyl methacrylate) (PMMA)-functionalized hexabenzocoronene (HBC). The HBC moiety was placed specifically at the PMMA chain-end such that the polymer chain-end can interact with the MWCNT through strong $\pi-\pi$ interactions [35]. The dispersion was then ultrasonicated for a few minutes and was allowed to settle for $24 \mathrm{~h}$ before use. MWCNTs that were not attached to the polymer settled at the bottom of the vial and were separated from the dispersion by decantation. The dispersion is stable over 30 days under ambient conditions (see Figure S1).

Planar heterojunction perovskite solar cells were fabricated in air by sequential deposition [13] of organic counterions onto the $\mathrm{PbI}_{2}$ thin film. $50 \mu \mathrm{L}$ of hot solution $\left(400 \mathrm{mg} \cdot \mathrm{mL}^{-1}\right)$ of lead iodide in DMF was spin coated on a pre-heated $\left(85^{\circ} \mathrm{C}\right)$ PEDOT:PSS-coated ITO substrate at $6000 \mathrm{rpm}$ for $35 \mathrm{s.} \mathrm{PbI}_{2}$-coated substrates were then annealed at $85^{\circ} \mathrm{C}$ for $45 \mathrm{~min}$. Mixed counterions (1:1 by wt. ratio) of methylammonium iodide (MAI) and formamidinium iodide (FAI) were dissolved in isopropanol $\left(40 \mathrm{mg} \cdot \mathrm{mL}^{-1}\right) .50 \mu \mathrm{L}$ of this solution was spin coated on top of $\mathrm{PbI}_{2}$ films at $6000 \mathrm{rpm}$ for $35 \mathrm{~s}$ at room temperature. Devices were then annealed at $85{ }^{\circ} \mathrm{C}$ for $45 \mathrm{~min}$ in the dark. MWCNT/perovskite composite devices were prepared from the $\mathrm{PbI}_{2}$ solution containing $0.005 \%$ and $0.01 \%$ of MWCNTs (by wt. to $\mathrm{PbI}_{2}$ ) in DMF keeping the $\mathrm{PbI}_{2}$ concentration approximately $400 \mathrm{mg} \cdot \mathrm{mL}^{-1}$. Powder x-ray diffraction (PXRD) revealed (see Figure S2) complete conversion to a trigonal ( $P 3 \mathrm{ml}$ ) perovskite phase for films fabricate with or without MWCNTs. A thin layer of PCBM was spin coated from a solution in chlorobenzene (20 $\mathrm{mg} \cdot \mathrm{mL}^{-1}$ ) at room temperature at $1000 \mathrm{rpm}$ for $60 \mathrm{~s}$ inside a $\mathrm{N}_{2}$-filled glove box. Finally, $15 \mathrm{~nm}$ of Ca at a deposition rate of $0.5 \AA \cdot \mathrm{s}^{-1}$ followed by $100 \mathrm{~nm}$ of Al electrode at a deposition rate of $1-3 \AA \cdot \mathrm{s}^{-1}$ were thermally deposited using a shadow mask of $6 \mathrm{~mm}^{2}$ active area at $1 \times 10^{-6} \mathrm{mbar}$.

\section{RESULTS AND DISCUSSION}

CNT bundles are often dispersed in a solvent using covalent chemical modification of the surface, conjugated polymers, or polymeric surfactants [36, 37]. Perovskite active layers are fabricated from solutions of lead and organic ammonium halide salts in polar solvents such as isopropanol or $N, N$-dimethylformamide (DMF). Thus, to incorporate MWCNTs in the bulk of the active layers, we needed MWCNT dispersions in polar solvents that are compatible with the active layer fabrication conditions. Moreover, the MWCNTs should preserve their electronic properties, and the interface between the MWCNT/perovskite should facilitate charge transfer. We recently reported a supramolecular strategy that uses $\pi-\pi$ interactions to non-covalently attach the chain end of a polymer to MWCNT [35]. Using this method, we were able to incorporate $0.005 \%$ and $0.01 \%$ of MWCNTs in the bulk of the perovskite layer. We chose MWCNTs because they are predominantly metallic and have high electrical conductivity compared 
to single-wall CNTs $[38,39]$. We verified the presence of MWCNTs in the $\mathrm{PbI}_{2}$ film using scanning electron microscopy (SEM) and conducting atomic force microscopy (cAFM) (see Figure 2). Most of the MWCNTs were expected to be in the bulk with no preferential orientation and only a few of them were expected to be oriented perpendicular to the film, thus spanning the entire film thickness. The presence of conducting MWCNTs in the film was detected by bright contrast due to charging in SEM. In cAFM, we observed higher current regions in the nonconducting $\mathrm{PbI}_{2}$ matrix indicating the presence of percolating pathways from the bottom electrode to the cAFM probe. Both observations are consistent with presence of MWCNTs in the $\mathrm{PbI}_{2}$ matrix. Further, the presence of MWCNTs in the films after conversion was confirmed with SEM. Figure S3 shows MWCNTs are in the grain boundaries of large perovskite grains, which are on the order of $1 \mu \mathrm{m}$.

Current density-voltage (J-V) measurements (Figure 3) were carried out in the dark as well as under AM1.5G solar simulator at $100 \mathrm{~mW} \cdot \mathrm{cm}^{-2}$ intensity of light in a $\mathrm{N}_{2}$-filled glove box. Dark $\mathrm{J}-\mathrm{V}$ measurements were carried out at a scan rate of $50 \mathrm{mV} \cdot \mathrm{s}^{-1}$ from reverse to forward bias as well as forward to reverse bias. No hysteresis was observed for devices containing $0.005 \%$ and $0.01 \%$ MWCNTs. However, perovskite solar cells containing no MWCNTs showed a small hysteresis in dark measurements (see Figure S4). J-V measurements under light were conducted by scanning the voltage from the forward bias to the reverse bias direction at a scan rate of $250 \mathrm{mV} \cdot \mathrm{s}^{-1} . \mathrm{J}-$ V curves under light were averaged over 9 devices containing MWCNTs at concentrations of $0 \%, 0.005 \%$ and $0.01 \%$, the averaged measurements are shown in Figure 3a. We focused on mixed counterions of MAI and FAI instead of $\mathrm{MAPbI}_{3}$ because they are reported to have superior photovoltaic performance [40]. Average and best device parameters are given in Table 1 for all three samples. The $\mathrm{V}_{\mathrm{oc}}(\sim 0.95 \mathrm{~V})$ was higher in devices containing MWCNTs compared to the reference $\left(0 \%\right.$ MWCNTs) solar cell $\mathrm{V}_{\mathrm{oc}}(0.88 \mathrm{~V})$. The maximum PCE of $12.9 \%$ was obtained from devices containing $0.005 \%$ MWCNTs. Further increase in MWCNTs in the perovskite matrix led to reduced current density and fill factor. Device performance histograms for 22 devices containing $0.005 \%$ MWCNT are shown in Figure 3c.

We first investigated the recombination losses in the perovskite films using electrochemical impedance spectroscopy (EIS). [41, 42] Figure 4 shows the Nyquist plot for samples containing 0\%, 0.005\%, and $0.01 \%$ MWCNTs at applied bias voltages $\left(\mathrm{V}_{\text {app }}\right)$ of $0 \mathrm{mV}$ and $900 \mathrm{mV}$ under AM1.5G solar simulator at $100 \mathrm{~mW} \cdot \mathrm{cm}^{-2}$ light intensity. Nyquist plots in the dark are shown in Figure S5. The Nyquist plots were analyzed using an equivalent electronic circuit model (Figure 4c) [41, 42]. To separate the ionic component from the electronic component, we 
introduced a Warburg diffusion element along with a charge transfer resistance $\left(\mathrm{R}_{\mathrm{CT}}\right)$ and a Debye layer capacitance $\left(\mathrm{C}_{\mathrm{dl}}\right)$ to the circuit model (Figure $\left.4 \mathrm{c}\right)$ [43]. The electronic component is represented by resistive $\left(\mathrm{R}_{\text {elect }}\right)$ and chemical capacitance $\left(\mathrm{C}_{\mu}\right)$ elements. Three distinct regimes are observed in the Nyquist plots under light: (1) a high-frequency regime related to the interfacial resistance and capacitance, (2) an intermediate-frequency regime related to charge transport and recombination, and (3) and a low-frequency regime related to charge accumulation and/or ion diffusion [41, 43-45]. To analyze the recombination and charge transport, we focused our analysis on the intermediate frequency regime of the Nyquist plots. When $\mathrm{V}_{\text {app }}=0 \mathrm{~V}$, the built-in internal electric field is high because it is not compensated by an applied voltage [46]. Under this condition, the dominant charge transport mode is drift and the measured resistance, $R_{\text {elect}}$, is dominated by charge recombination resistance $\left(R_{\text {rec }}\right)$ [47]. As seen in Figure $4 \mathrm{a}$, as the concentration of MWCNTs increase, $\mathrm{R}_{\mathrm{rec}}$ also increases consistent with reduced recombination and efficient charge collection [48]. At $\mathrm{V}_{\text {app }}=900 \mathrm{mV}$, the applied voltage is close to the $\mathrm{V}_{\text {oc }}$. Under this condition, the internal electric field decreases and the charge transport is dominated by diffusion. The measured resistance, $R_{\text {elect }}$ is dominated by charge transport resistance $\left(R_{t r}\right)$ as shown in Figure $4 b . R_{t r}$ decreases as the percentage of MWCNTs is increased in the perovskite matrix, indicating better charge transport (Figure $4 \mathrm{~b}$ ). In active layer containing $0.01 \%$ MWCNTs, the hole mobility is expected to be higher than the electron mobility due to the high hole mobility in MWCNTs [49]. These experimental results are also consistent with our simulation results that predict high hole mobility in devices containing $0.01 \%$ MWCNTs.

We then examined the charge carrier concentration of the three samples at the perovskite/HTM interface from the slope of the Mott-Schottky (M-S) plot as shown in Figure 5 under AM1.5G solar simulator at $100 \mathrm{~mW} \cdot \mathrm{cm}^{-2}$ light intensity. The photo-generated charge carrier concentration at the perovskite/HTM interface is inversely proportional to the slope of the linear regime of the M-S plot assuming the dielectric constant is the same for all three samples. The ratio of the slopes of the linear regime of the M-S plot was 1:1.8:2.3 for $0 \%, 0.005 \%$ and $0.01 \%$ MWCNTs respectively indicating that the photo-generated charge accumulation is reduced by a factor of two at the perovskite/HTM interface when the MWCNT content was increased to $0.005 \%$. These results are consistent with the EIS results and the simulation that showed that charge extraction rate at the perovskite/PEDOT:PSS interface was improved upon introduction of MWCNTs.

\section{THEORY AND CALCULATIONS}


To understand the origin of the increase in $\mathrm{V}_{\mathrm{oc}}$ in the presence of MWCNTs in perovskite solar cells, we first carried out charge transport simulations in the devices examined by implementing a drift-diffusion-reaction model that is detailed in SI. The parameter values obtained in the simulations are given in Table 2 and discussed in SI; the simulation results are compared with the experimental J-V measurements in Figure 6. We assumed a comparable electron and hole mobility $\left(\sim 1 \times 10^{-4} \mathrm{~m}^{2} \mathrm{~V}^{-1} \mathrm{~s}^{-1}\right)$ in perovskite solar cells without any MWCNTs introduced in the active layer [50, 51], whereas the mobility of electrons and holes in PCBM [52] and PEDOT:PSS [53], respectively, were taken to be at least four orders of magnitude lower than in the perovskite active layer. We observed a significant reduction (at least 87\%) in recombination loss in active layers containing MWCNTs. The simulation indicated that the hole mobility was four times higher than the electron mobility for devices containing $0.01 \%$ MWCNTs whereas the mobilities are comparable in devices containing $0 \%$ and $0.005 \%$ MWCNTs. Moreover, the bulk defect density was calculated to be about 9 times higher in devices containing $0.01 \%$ MWCNTs compared to devices with $0 \%$ MWCNTs. Our simulations also indicated that the charge extraction rate at the perovskite/PEDOT:PSS interface was improved upon introduction of MWCNTs in the active layer.

Next, we probed the impact of MWCNTs on defect or trap state densities by analyzing the J-V device characteristics under dark. The dark J-V device characteristics for the three samples containing $0 \%, 0.005 \%$ and 0.01\% MWCNTs are shown in Figure 3b. We found that the dark current in the reverse voltage bias regime increased with MWCNT concentration and is consistent with increasing leakage current. A fit of the dark J-V curves to a diode equation indicates all samples show a non-ideal behavior (ideality factor, $n>1$ ) (see Figure S6 and Table S1). The ideality factor was calculated to be $1.71,1.73$ and 5.32 for samples containing $0 \%, 0.005 \%$ and $0.01 \%$ MWCNTs respectively. Both the increase in the leakage current and the ideality factor result from the increase of trap states introduced by the incorporation of MWCNTs. In the high forward voltage regime, the current densities for the three samples are comparable, indicating that the serial resistances of these devices are comparable and are not affected by the incorporation of the MWCNTs into the perovskite bulk.

Our simulations and experiments indicate that introduction of MWCNTs in the bulk of perovskite active layers leads to (1) reduction in charge recombination, (2) improved charge extraction at the electrode/HTL interface, and (3) increase in the trap states leading to increased leakage current and ideality factor. We also find that that the presence of $0.005 \%$ MWCNTs provided the best overall device performance. The device performance improves with reduced charge recombination and improved charge extraction, but may diminish with increase in the trap 
states. For example, an increase in trap states leads to increase in both $\mathrm{J}_{\mathrm{SC}}$ and $n$. Increase in $n$ will lead to higher $\mathrm{V}_{\mathrm{oc}}$ whereas increase in $\mathrm{J}_{\mathrm{SC}}$ will lead to lower $\mathrm{V}_{\mathrm{oc}}[54]$. Therefore, we conclude that a MWCNT concentration of $0.005 \%$ by wt. is a reasonable estimate of the optimal MWCNT concentration for a planar inverted perovskite device architecture that provides a balanced hole and electron transport with reduced bulk recombination loss and minimal introduction of trap states. Only a low concentration $(0.005 \%)$ of MWCNTs is required to reduce the recombination rate as the hole diffusion length is significantly high in perovskite materials [50]. Efficient charge collection at the interface and reduced recombination loss increases $\mathrm{V}_{\mathrm{oc}}$ and the overall PCE [17]. Our results are also consistent with a recent observation that the incorporation of CNTs in the active layers improves photoluminescence lifetime and thus device performance [55].

\section{CONCLUSIONS}

In this letter, we have demonstrated a facile route for the synthesis of perovskite/MWCNT materials for high efficiency photovoltaics. MWCNTs introduced into the perovskite active layer not only facilitate charge transport, but also reduce charge carrier recombination losses by $>87 \%$ in the bulk due to separation of charges at the perovskite/MWCNT interfaces. The reduction in recombination losses due to selective charge transport in the bulk generates opportunities for further material engineering towards higher PCE. This approach of CNT incorporation into the perovskite matrix is compatible to both conventional and inverted device geometries. It also opens up future directions to tune electron and hole mobility in CNT/perovskite composite nanomaterials.

\section{ACKNOWLEDGMENTS}

The authors acknowledge support from Polymer-Based Materials for Harvesting Solar Energy (PHaSE), an Energy Frontier Research Center (EFRC) funded by the U.S. Department of Energy, Office of Science, Basic Energy Sciences under Award No. DE-SC0001087. The authors also acknowledge SEM and AFM use through the W.M. Keck Electron Microscopy and Nanostructures Laboratory, which is partially supported by the U.S. National Science Foundation Materials Research Science and Engineering Center (MRSEC) on Polymers, Award No. DMR0820506.

\section{ABBREVIATIONS}

MWCNT, Multi-walled carbon nanotube; PCBM, Phenyl-C ${ }_{61}$-butyric acid methyl ester; HBC, Hexabenzocoronene; EIS, Electrochemical impedance spectroscopy.

\section{APPENDIX A}


Supplementary data for this publication can be found online at http://

\section{REFERENCES}

[1] L. Etgar, P. Gao, Z. Xue, Q. Peng, A.K. Chandiran, B. Liu, M.K. Nazeeruddin, M. Grätzel, Mesoscopic $\mathrm{CH}_{3} \mathrm{NH}_{3} \mathrm{PbI}_{3} / \mathrm{TiO}_{2}$ heterojunction solar cells, J. Am. Chem. Soc. 134 (2012) 17396-17399.

[2] M.A. Green, A. Ho-Baillie, H.J. Snaith, The emergence of perovskite solar cells, Nat. Photon. 8 (2014) 506-514.

[3] J.H. Heo, S.H. Im, J.H. Noh, T.N. Mandal, C.-S. Lim, J.A. Chang, Y.H. Lee, H.-j. Kim, A. Sarkar, K. NazeeruddinMd, M. Grätzel, S.I. Seok, Efficient inorganic-organic hybrid heterojunction solar cells containing perovskite compound and polymeric hole conductors, Nat. Photon. 7 (2013) 486-491.

[4] N.J. Jeon, J.H. Noh, Y.C. Kim, W.S. Yang, S. Ryu, S.I. Seok, Solvent engineering for high-performance inorganic-organic hybrid perovskite solar cells, Nat. Mater. 13 (2014) 897-903.

[5] M.M. Lee, J. Teuscher, T. Miyasaka, T.N. Murakami, H.J. Snaith, Efficient hybrid solar cells based on mesosuperstructured organometal halide perovskites, Science 338 (2012) 643-647.

[6] M. Liu, M.B. Johnston, H.J. Snaith, Efficient planar heterojunction perovskite solar cells by vapour deposition, Nature 501 (2013) 395-398.

[7] M.D. McGehee, Perovskite solar cells: Continuing to soar, Nat. Mater. 13 (2014) 845-846.

[8] Q.Q. Lin, A. Armin, P.L. Burn, P. Meredith, Organohalide perovskites for solar energy conversion, Accounts Chem. Res. 49 (2016) 545-553.

[9] L. Meng, J.B. You, T.F. Guo, Y. Yang, Recent advances in the inverted planar structure of perovskite solar cells, Accounts Chem. Res. 49 (2016) 155-165.

[10] H. Zhou, Q. Chen, G. Li, S. Luo, T.-b. Song, H.-S. Duan, Z. Hong, J. You, Y. Liu, Y. Yang, Interface engineering of highly efficient perovskite solar cells, Science 345 (2014) 542-546.

[11] W. Nie, H. Tsai, R. Asadpour, J.-C. Blancon, A.J. Neukirch, G. Gupta, J.J. Crochet, M. Chhowalla, S. Tretiak, M.A. Alam, H.-L. Wang, A.D. Mohite, High-efficiency solution-processed perovskite solar cells with millimeterscale grains, Science 347 (2015) 522-525.

[12] J. You, Z. Hong, Y. Yang, Q. Chen, M. Cai, T.-B. Song, C.-C. Chen, S. Lu, Y. Liu, H. Zhou, Low-temperature solution-processed perovskite solar cells with high efficiency and flexibility, ACS Nano 8 (2014) 1674-1680.

[13] J. Burschka, N. Pellet, S.-J. Moon, R. Humphry-Baker, P. Gao, M.K. Nazeeruddin, M. Grätzel, Sequential deposition as a route to high-performance perovskite-sensitized solar cells, Nature 499 (2013) 316-319. 
[14] J. Seo, S. Park, Y. Chan Kim, N.J. Jeon, J.H. Noh, S.C. Yoon, S.I. Seok, Benefits of very thin PCBM and LiF layers for solution-processed p-i-n perovskite solar cells, Energ. Environ. Sci. 7 (2014) 2642-2646.

[15] G. Xing, N. Mathews, S. Sun, S.S. Lim, Y.M. Lam, M. Grätzel, S. Mhaisalkar, T.C. Sum, Long-range balanced electron- and hole-transport lengths in organic-inorganic $\mathrm{CH}_{3} \mathrm{NH}_{3} \mathrm{PbI}_{3}$, Science 342 (2013) 344-347.

[16] Y. Zhao, K. Zhu, Charge transport and recombination in perovskite $\left(\mathrm{CH}_{3} \mathrm{NH}_{3}\right) \mathrm{PbI}_{3}$ sensitized $\mathrm{TiO}_{2}$ solar cells, J. Phys. Chem. Lett. 4 (2013) 2880-2884.

[17] B. Suarez, V. Gonzalez-Pedro, T.S. Ripolles, R.S. Sanchez, L. Otero, I. Mora-Sero, Recombination study of combined halides (Cl, Br, I) perovskite solar cells, J. Phys. Chem. Lett. 5 (2014) 1628-1635.

[18] W. Yang, Y. Yao, C.-Q. Wu, Origin of the high open circuit voltage in planar heterojunction perovskite solar cells: Role of the reduced bimolecular recombination, J. Appl. Phys. 117 (2015) 095502.

[19] E.J. Juarez-Perez, M. Wußler, F. Fabregat-Santiago, K. Lakus-Wollny, E. Mankel, T. Mayer, W. Jaegermann, I. Mora-Sero, Role of the selective contacts in the performance of lead halide perovskite solar cells, J. Phys. Chem. Lett. 5 (2014) 680-685.

[20] E. Edri, S. Kirmayer, A. Henning, S. Mukhopadhyay, K. Gartsman, Y. Rosenwaks, G. Hodes, D. Cahen, Why lead methylammonium tri-iodide perovskite-based solar cells require a mesoporous electron transporting scaffold (but not necessarily a hole conductor), Nano Lett. 14 (2014) 1000-1004.

[21] H.-S. Kim, J.-W. Lee, N. Yantara, P.P. Boix, S.A. Kulkarni, S. Mhaisalkar, M. Grätzel, N.-G. Park, High efficiency solid-state sensitized solar cell-based on submicrometer rutile $\mathrm{TiO}_{2}$ nanorod and $\mathrm{CH}_{3} \mathrm{NH}_{3} \mathrm{PbI}_{3}$ perovskite sensitizer, Nano Lett. 13 (2013) 2412-2417.

[22] N.J. Jeon, H.G. Lee, Y.C. Kim, J. Seo, J.H. Noh, J. Lee, S.I. Seok, O-methoxy substituents in spiro-ometad for efficient inorganic-organic hybrid perovskite solar cells, J. Am. Chem. Soc. 136 (2014) 7837-7840.

[23] C. Kuang, G. Tang, T. Jiu, H. Yang, H. Liu, B. Li, W. Luo, X. Li, W. Zhang, F. Lu, J. Fang, Y. Li, Highly efficient electron transport obtained by doping PCBM with graphdiyne in planar-heterojunction perovskite solar cells, Nano Lett. 15 (2015) 2756-2762.

[24] F. Hou, Z. Su, F. Jin, X. Yan, L. Wang, H. Zhao, J. Zhu, B. Chu, W. Li, Efficient and stable planar heterojunction perovskite solar cells with a $\mathrm{MoO}_{3} /$ PEDOT:PSS hole transporting layer, Nanoscale (2015) 94279432. 
[25] Z. Zhu, J. Ma, Z. Wang, C. Mu, Z. Fan, L. Du, Y. Bai, L. Fan, H. Yan, D.L. Phillips, Efficiency enhancement of perovskite solar cells through fast electron extraction: The role of graphene quantum dots, J. Am. Chem. Soc. 136 (2014) 3760-3763.

[26] Z. Yang, J. Ren, Z. Zhang, X. Chen, G. Guan, L. Qiu, Y. Zhang, H. Peng, Recent advancement of nanostructured carbon for energy applications, Chem. Rev. 115 (2015) 5159-5223.

[27] X. Wang, Z. Li, W. Xu, S.A. Kulkarni, S.K. Batabyal, S. Zhang, A. Cao, L.H. Wong, $\mathrm{TiO}_{2}$ nanotube arrays based flexible perovskite solar cells with transparent carbon nanotube electrode, Nano Energ. 11 (2015) 728-735.

[28] Z. Li, S.A. Kulkarni, P.P. Boix, E. Shi, A. Cao, K. Fu, S.K. Batabyal, J. Zhang, Q. Xiong, L.H. Wong, Laminated carbon nanotube networks for metal electrode-free efficient perovskite solar cells, ACS Nano 8 (2014) 6797-6804.

[29] M. Cai, V.T. Tiong, T. Hreid, J. Bell, H. Wang, An efficient hole transport material composite based on poly (3-hexylthiophene) and bamboo-structured carbon nanotubes for high performance perovskite solar cells, J. Mater. Chem. A. 3 (2015) 2784-2793.

[30] S.N. Habisreutinger, T. Leijtens, G.E. Eperon, S.D. Stranks, R.J. Nicholas, H.J. Snaith, Carbon nanotube/polymer composites as a highly stable hole collection layer in perovskite solar cells, Nano Lett. 14 (2014) 5561-5568.

[31] S.N. Habisreutinger, T. Leijtens, G.E. Eperon, S.D. Stranks, R.J. Nicholas, H.J. Snaith, Enhanced hole extraction in perovskite solar cells through carbon nanotubes, J. Phys. Chem. Lett. 5 (2014) 4207-4212.

[32] Z.H. Wei, H.N. Chen, K.Y. Yan, X.L. Zheng, S.H. Yang, Hysteresis-free multi-walled carbon nanotube-based perovskite solar cells with a high fill factor, J. Mater. Chem. A. 3 (2015) 24226-24231.

[33] Z. Li, P.P. Boix, G.C. Xing, K.W. Fu, S.A. Kulkarni, S.K. Batabyal, W.J. Xu, A.Y. Cao, T.C. Sum, N. Mathews, L.H. Wong, Carbon nanotubes as an efficient hole collector for high voltage methylammonium lead bromide perovskite solar cells, Nanoscale 8 (2016) 6352-6360.

[34] P. Schulz, A.M. Dowgiallo, M.J. Yang, K. Zhu, J.L. Blackburn, J.J. Berry, Charge transfer dynamics between carbon nanotubes and hybrid organic metal halide perovskite films, J. Phys. Chem. Lett. 7 (2016) 418-425.

[35] S.P. Jeong, C.J. Boyle, D. Venkataraman, Poly(methyl methacrylate) end-functionalized with hexabenzocoronene as an effective dispersant for multi-walled carbon nanotubes, RSC Adv. 6 (2016) 6107-6110. 
[36] P.C. Ma, N.A. Siddiqui, G. Marom, J.K. Kim, Dispersion and functionalization of carbon nanotubes for polymer-based nanocomposites: A review, Compos. Pt. A-Appl. Sci. Manuf. 41 (2010) 1345-1367.

[37] S.K. Samanta, M. Fritsch, U. Scherf, W. Gomulya, S.Z. Bisri, M.A. Loi, Conjugated polymer-assisted dispersion of single-wall carbon nanotubes: The power of polymer wrapping, Accounts Chem. Res. 47 (2014) 24462456.

[38] Y.J. Kim, T.S. Shin, H. Do Choi, J.H. Kwon, Y.-C. Chung, H.G. Yoon, Electrical conductivity of chemically modified multiwalled carbon nanotube/epoxy composites, Carbon 43 (2005) 23-30.

[39] Y. Ando, X. Zhao, H. Shimoyama, G. Sakai, K. Kaneto, Physical properties of multiwalled carbon nanotubes, Int. J. Inorg. Mater. 1 (1999) 77-82.

[40] N. Pellet, P. Gao, G. Gregori, T.Y. Yang, M.K. Nazeeruddin, J. Maier, M. Grätzel, Mixed-organic-cation perovskite photovoltaics for enhanced solar-light harvesting, Angew. Chem. Int. Ed. 53 (2014) 3151-3157.

[41] V. Gonzalez-Pedro, E.J. Juarez-Perez, W.-S. Arsyad, E.M. Barea, F. Fabregat-Santiago, I. Mora-Sero, J. Bisquert, General working principles of $\mathrm{ch}_{3} \mathrm{nh}_{3} \mathrm{pbx}_{3}$ perovskite solar cells, Nano Lett. 14 (2014) 888-893.

[42] L. Bertoluzzi, P.P. Boix, I. Mora-Sero, J. Bisquert, Theory of impedance spectroscopy of ambipolar solar cells with trap-mediated recombination, J. Phys. Chem. C. 118 (2014) 16574-16580.

[43] M. Bag, L.A. Renna, R.Y. Adhikari, S. Karak, F. Liu, P.M. Lahti, T.P. Russell, M.T. Tuominen, D. Venkataraman, Kinetics of ion transport in perovskite active layers and its implications for active layer stability, J. Am. Chem. Soc. 137 (2015) 13130-13137.

[44] Z. Xiao, Y. Yuan, Y. Shao, Q. Wang, Q. Dong, C. Bi, P. Sharma, A. Gruverman, J. Huang, Giant switchable photovoltaic effect in organometal trihalide perovskite devices, Nat. Mater. 14 (2015) 193-198.

[45] H.-S. Kim, I. Mora-Sero, V. Gonzalez-Pedro, F. Fabregat-Santiago, E.J. Juarez-Perez, N.-G. Park, J. Bisquert, Mechanism of carrier accumulation in perovskite thin-absorber solar cells, Nat. Commun. 4 (2013) Article No. 2242.

[46] V.D. Mihailetchi, L.J.A. Koster, J.C. Hummelen, P.W.M. Blom, Photocurrent generation in polymer-fullerene bulk heterojunctions, Phys. Rev. Lett. 93 (2004) 216601.

[47] P.P. Boix, G. Larramona, A. Jacob, B. Delatouche, I. Mora-Seró, J. Bisquert, Hole transport and recombination in all-solid $\mathrm{Sb}_{2} \mathrm{~S}_{3}$-sensitized $\mathrm{TiO}_{2}$ solar cells using CuSCN as hole transporter, J. Phys. Chem. C. 116 (2011) 15791587. 
[48] A.R. Pascoe, N.W. Duffy, A.D. Scully, F. Huang, Y.-B. Cheng, Insights into planar $\mathrm{CH}_{3} \mathrm{NH}_{3} \mathrm{PbI}_{3}$ perovskite solar cells using impedance spectroscopy, J. Phys. Chem. C. 119 (2015) 4444-4453.

[49] T. Dürkop, S.A. Getty, E. Cobas, M.S. Fuhrer, Extraordinary mobility in semiconducting carbon nanotubes, Nano Lett. 4 (2004) 35-39.

[50] S.D. Stranks, G.E. Eperon, G. Grancini, C. Menelaou, M.J.P. Alcocer, T. Leijtens, L.M. Herz, A. Petrozza, H.J. Snaith, Electron-hole diffusion lengths exceeding 1 micrometer in an organometal trihalide perovskite absorber, Science 342 (2013) 341-344.

[51] T.J. Savenije, C.S. Ponseca Jr, L. Kunneman, M. Abdellah, K. Zheng, Y. Tian, Q. Zhu, S.E. Canton, I.G. Scheblykin, T. Pullerits, Thermally activated exciton dissociation and recombination control the carrier dynamics in organometal halide perovskite, J. Phys. Chem. Lett. 5 (2014) 2189-2194.

[52] Y. Shao, Z. Xiao, C. Bi, Y. Yuan, J. Huang, Origin and elimination of photocurrent hysteresis by fullerene passivation in $\mathrm{CH}_{3} \mathrm{NH}_{3} \mathrm{PbI}_{3}$ planar heterojunction solar cells, Nat. Commun. 5 (2014) Article No. 5784.

[53] H.-J. Jhuo, P.-N. Yeh, S.-H. Liao, Y.-L. Li, S. Sharma, S.-A. Chen, Inverted perovskite solar cells with inserted cross-linked electron-blocking interlayers for performance enhancement, J. Mater. Chem. A. 3 (2015) 9291-9297.

[54] J. Nelson, The physics of solar cells, World Scientific2003.

[55] Y. Zhang, L.C. Tan, Q.X. Fu, L. Chen, T. Ji, X.T. Hu, Y.W. Chen, Enhancing the grain size of organic halide perovskites by sulfonate-carbon nanotube incorporation in high performance perovskite solar cells, Chem. Commun. 52 (2016) 5674-5677. 

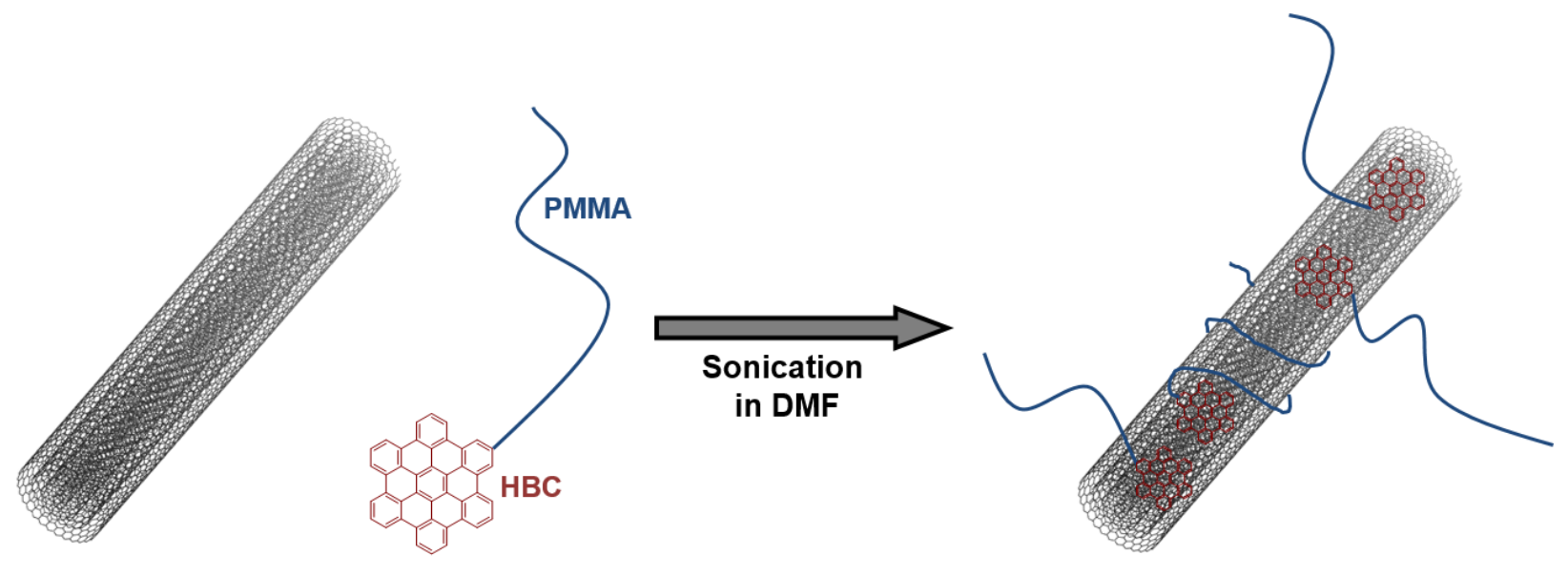

Figure 1. Schematic representation of HBC-PMMA-grafted MWCNT.

To be reproduced in color on the Web and in black-and-white in print. Black-and-white image provided on Page 21 

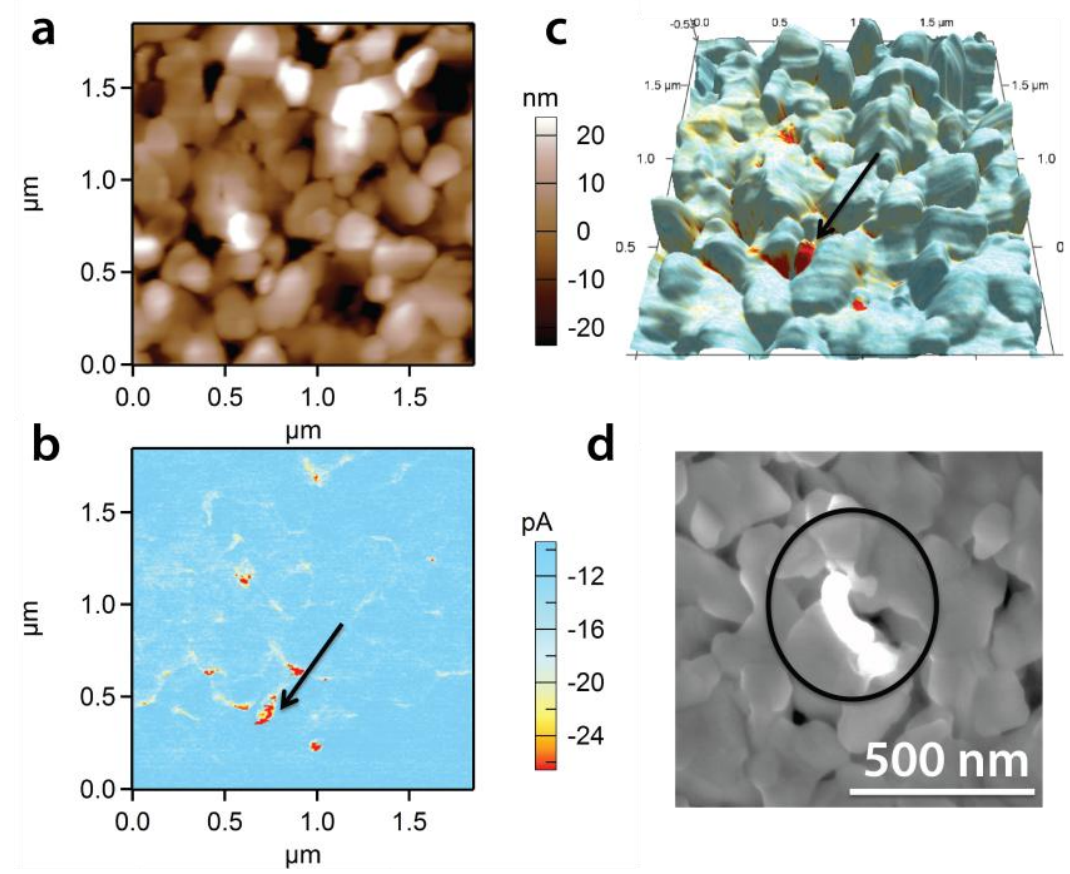

Figure 2. (a) AFM topographic image of $\mathrm{PbI}_{2} / \mathrm{MWCNT}$ composite film on PEDOT:PSS-coated ITO substrate. (b) cAFM image of the same area. (c) Topographic image superimposed onto current mapping from cAFM. High current regions are from MWCNTs. (d) SEM image of $\mathrm{PbI}_{2} / \mathrm{MWCNTs}$ composite film on Si substrate. A MWCNT is highlighted with a circle.

To be reproduced in color on the Web and in black-and-white in print. Black-and-white image provided on Page 22 

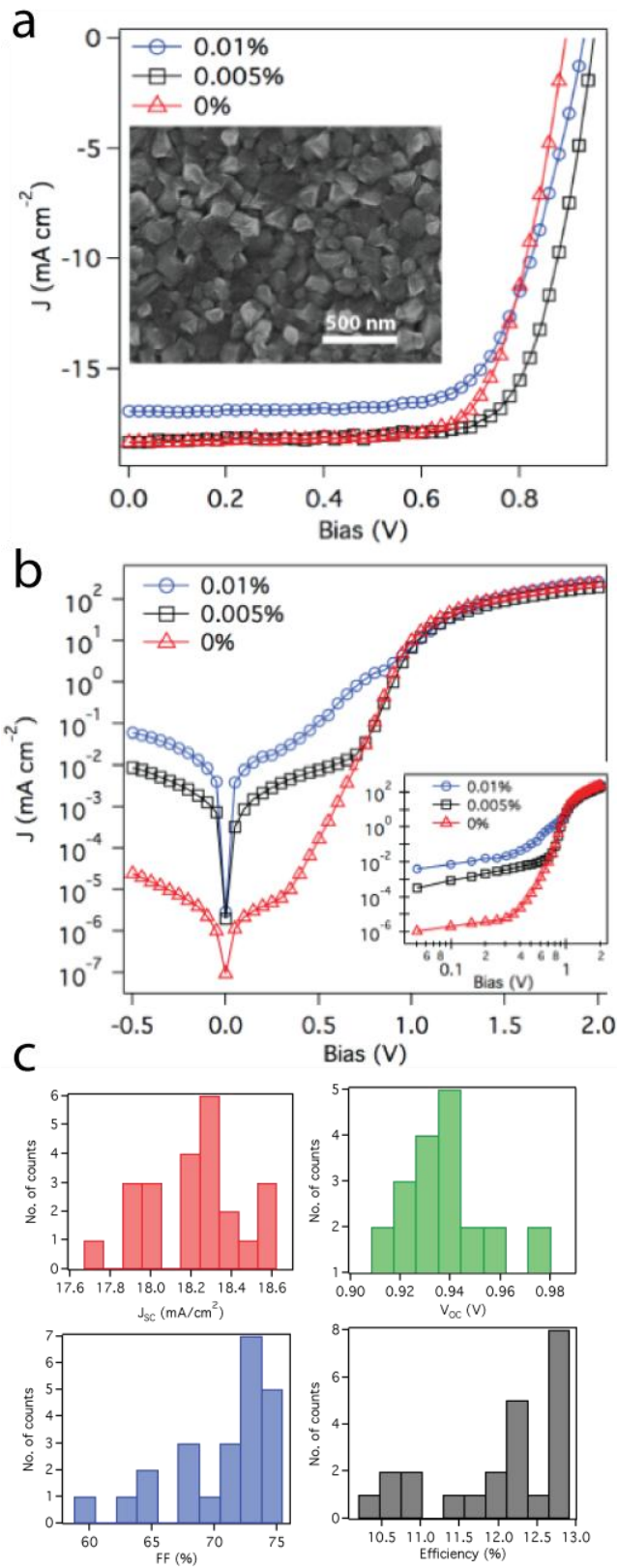

Figure 3. (a) J-V curves from steady exposure to light of three lead tri-iodide-based perovskite photovoltaic devices with active layers containing $0 \%, 0.005 \%$ and $0.01 \%$ MWCNTs (by wt. to $\mathrm{PbI}_{2}$ ) averaged over 9 samples from different substrates of the same batch of experiments. Inset: Top SEM image of perovskite sample containing no CNTs. (b) Dark J-V characteristics of perovskite photovoltaic devices with active layers containing 0\% (red triangles), $0.005 \%$ (black squares) and $0.01 \%$ (blue circles) of MWCNTs. The inset shows a log-log plot of the dark J-V curves. (c) Device performance histograms for 22 devices containing $0.005 \%$ MWCNT.

To be reproduced in color on the Web and in black-and-white in print. Black-and-white image provided on Page 23 


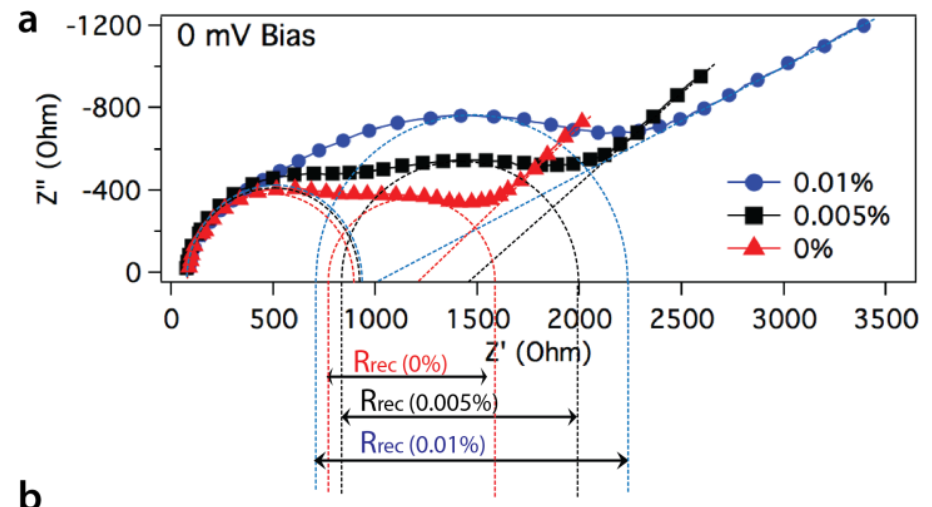

b
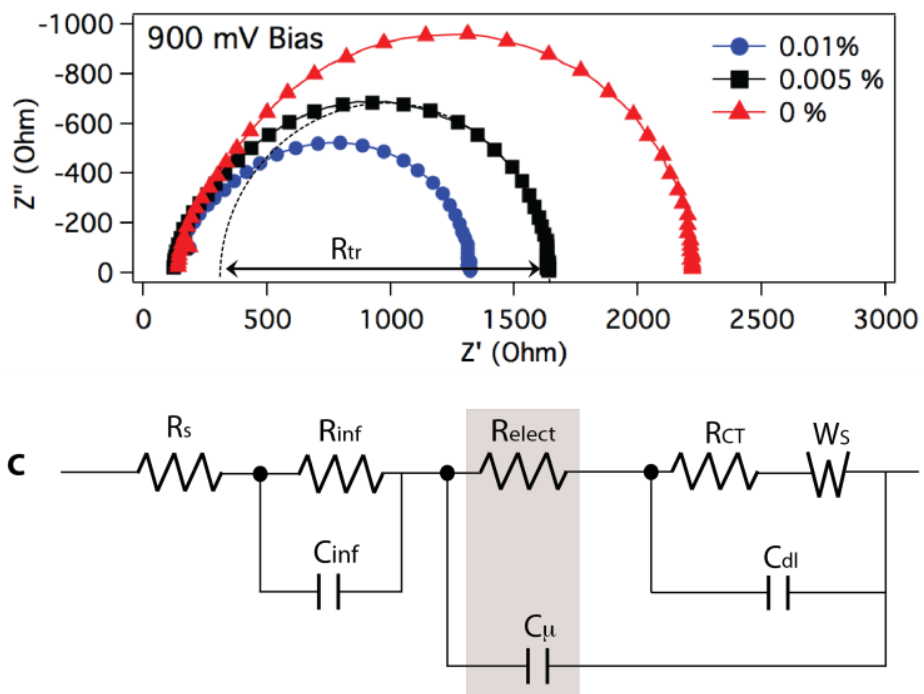

Figure 4. EIS plot of perovskite solar cells under AM1.5G solar simulator at $100 \mathrm{~mW} \cdot \mathrm{cm}^{-2}$ light intensity at a bias voltage of (a) $0 \mathrm{~V}$ and (b) $900 \mathrm{mV}$. The frequency range is from $100 \mathrm{~Hz}$ to $1 \mathrm{MHz}$ at $20 \mathrm{mV}$ AC amplitude. (c) Equivalent circuit diagram for the perovskite solar cell. $\mathrm{R}_{\text {elect }}$ represents the electronic transport component and $\mathrm{W}_{\mathrm{S}}$ represents the Warburg diffusion element. The shaded area represents the intermediate-frequency component of the Nyquist plot.

To be reproduced in color on the Web and in black-and-white in print. Black-and-white image provided on Page 24 


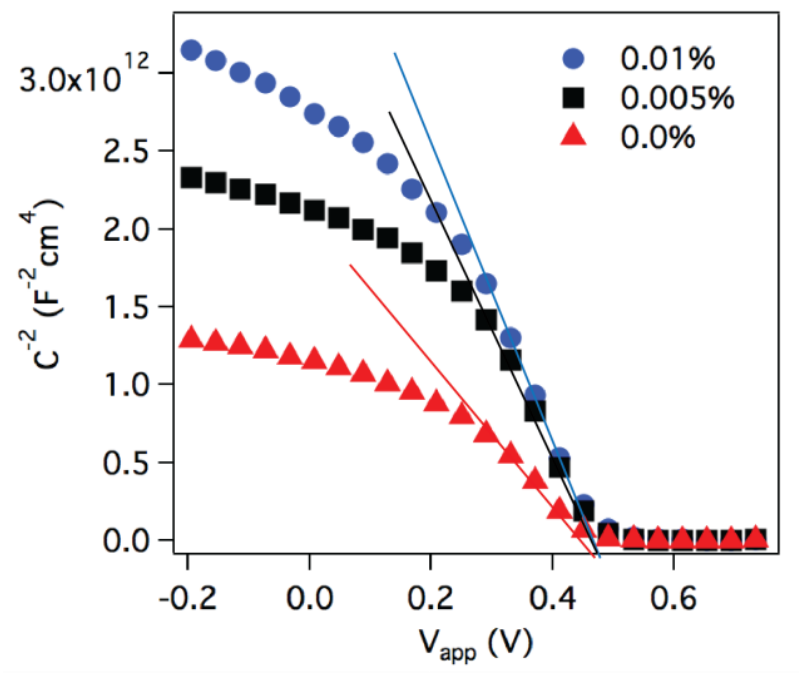

Figure 5. Mott-Schottky plot of lead tri-halide perovskite solar cells containing MWCNTs at concentrations of $0 \%$, $0.005 \%$ and $0.01 \%$ (by wt. to $\mathrm{PbI}_{2}$ ) in the bulk of the perovskite films at $100 \mathrm{~mW} \cdot \mathrm{cm}^{-2}$ light intensity. Capacitance was measured at a $10 \mathrm{kHz}$ oscillation frequency with $20 \mathrm{mV}$ AC amplitude.

To be reproduced in color on the Web and in black-and-white in print. Black-and-white image provided on Page 25 


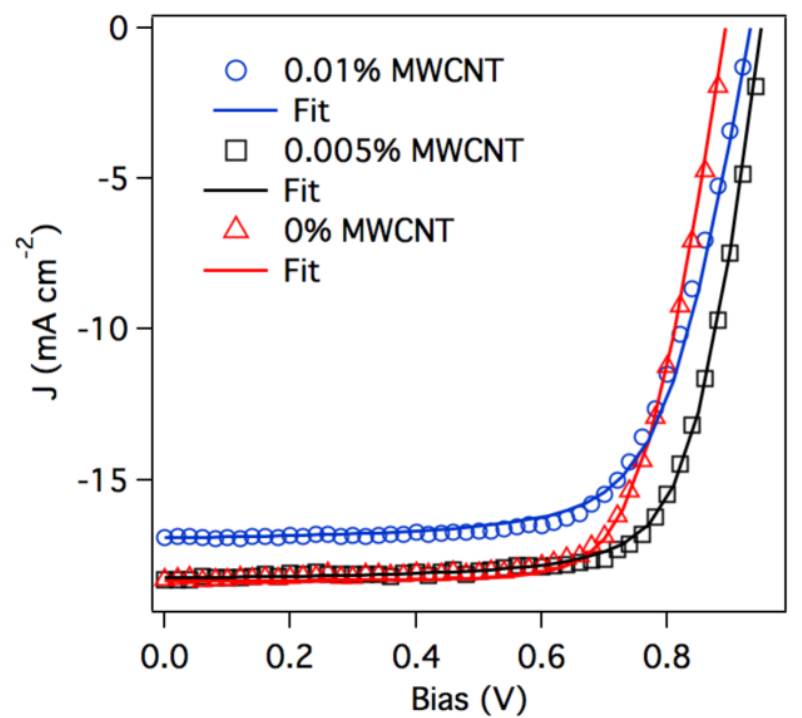

Figure 6. (a) Best fitting of simulation predictions according to the drift-diffusion-reaction model (solid lines) to the experimentally measured $\mathrm{J}-\mathrm{V}$ characteristics (open symbols) in perovskite photovoltaic devices for $0 \%, 0.005 \%$ and $0.01 \%$ (by wt. to $\mathrm{PbI}_{2}$ ) concentration of MWCNTs in the active layer.

To be reproduced in color on the Web and in black-and-white in print. Black-and-white image provided on Page 26 
Table 1: Performance of lead tri-iodide-based perovskite solar cells containing $0 \%, 0.005 \%$ and $0.01 \%$ MWCNTs in the active layer. Average values are reported from 9 best devices of multiple substrates.

\begin{tabular}{|c|c|c|c|c|}
\hline Device condition & $\begin{array}{l}J_{\mathrm{sc}} \\
\left(m A-\mathrm{cm}^{-2}\right)\end{array}$ & $\begin{array}{l}V_{\mathrm{oc}} \\
(V)\end{array}$ & $\begin{array}{l}F F \\
(\%)\end{array}$ & $\begin{array}{l}\eta \\
(\%)\end{array}$ \\
\hline $0.0 \%$ CNT (Avg.) & $18.15 \pm 0.5$ & $0.885 \pm 0.005$ & $72.6 \pm 1$ & $11.7 \pm 0.4$ \\
\hline Best cell & 18.66 & 0.883 & 73.3 & 12.09 \\
\hline $0.005 \%$ CNT (Avg.) & $18.27 \pm 0.2$ & $0.95 \pm 0.02$ & $73.0 \pm 2$ & $12.7 \pm 0.4$ \\
\hline Best cell & 18.28 & 0.97 & 72.8 & 12.91 \\
\hline $0.01 \%$ CNT (Avg.) & $16.82 \pm 0.3$ & $0.92 \pm 0.02$ & $69.0 \pm 2$ & $10.7 \pm 0.2$ \\
\hline Best cell & 16.84 & 0.934 & 69.6 & 10.96 \\
\hline
\end{tabular}


Table 2: Optimal parameter values obtained from fitting the simulation predictions according to the drift-diffusionreaction model to the experimental $\mathrm{J}-\mathrm{V}$ data for perovskite samples containing $0 \%, 0.005 \%$ and $0.01 \%$ MWCNTs in the active layer. All of the parameters are defined in SI, where the drift-diffusion-reaction model is described in detail.

\begin{tabular}{l|l|l|l|l}
\hline Parameters & & $\begin{array}{l}0 \% \\
M W C N T\end{array}$ & $\begin{array}{l}0.005 \% \\
M W C N T\end{array}$ & $\begin{array}{l}0.01 \% \\
M W C N T\end{array}$ \\
\hline Charge generation & $\mathrm{G}_{0}\left(\times 10^{27} \mathrm{~m}^{-3} \mathrm{~s}^{-1}\right)$ & 3.8 & 3.8 & 3.53 \\
Perovskite relative permittivity & $\varepsilon_{\text {perovskite }}$ & 6.5 & 6.5 & 6.5 \\
Electron mobility in PCBM & $\mu_{\mathrm{n}}\left(\times 10^{-8} \mathrm{~m}^{2} \mathrm{~V}^{-1} \mathrm{~s}^{-1}\right)$ & 2.4 & 2.4 & 2.4 \\
Hole mobility in PEDOT:PSS & $\mu_{\mathrm{p}}\left(\times 10^{-8} \mathrm{~m}^{2} \mathrm{~V}^{-1} \mathrm{~s}^{-1}\right)$ & 2.4 & 2.4 & 2.4 \\
Electron mobility in perovskite & $\mu_{\mathrm{n}}\left(\times 10^{-4} \mathrm{~m}^{2} \mathrm{~V}^{-1} \mathrm{~s}^{-1}\right)$ & 1.0 & 1.0 & 1.0 \\
Hole mobility in perovskite & $\mu_{\mathrm{p}}\left(\times 10^{-4} \mathrm{~m}^{2} \mathrm{~V}^{-1} \mathrm{~s}^{-1}\right)$ & 1.0 & 1.0 & $\mathbf{4 . 0}$ \\
$\begin{array}{l}\text { Intrinsic carrier density } \\
\text { Recombination coefficient }\end{array}$ & $\mathrm{n}_{\mathrm{i}}\left(\times 10^{15} \mathrm{~m}^{-3}\right)$ & 6.5 & 6.5 & 6.5 \\
$\begin{array}{l}\text { at PCBM/perovskite interface } \\
\text { Recombination coefficient } \\
\text { at PEDOT:PSS/perovskite interface }\end{array}$ & $\mathrm{C}_{\mathrm{PCBM} / \text { Perovskite }}$ & 1.0 & 1.0 & 1.0 \\
$\begin{array}{l}\text { Bulk recombination coefficient } \\
\text { in perovskite layer }\end{array}$ & $\mathrm{C}_{\mathrm{PEDOT}: \mathrm{PSS} / \text { Perovskite }}$ & $\mathbf{1 . 0}$ & $\mathbf{0 . 5}$ & $\mathbf{0 . 2}$ \\
Bulk defect density & $\mathrm{C}_{\text {perovskite }}\left(\times 10^{-8}\right)$ & $\mathbf{4 . 5}$ & $\mathbf{0 . 5 7}$ & $\mathbf{0 . 5}$ \\
\hline
\end{tabular}




\section{Black and White Pictures for Print}

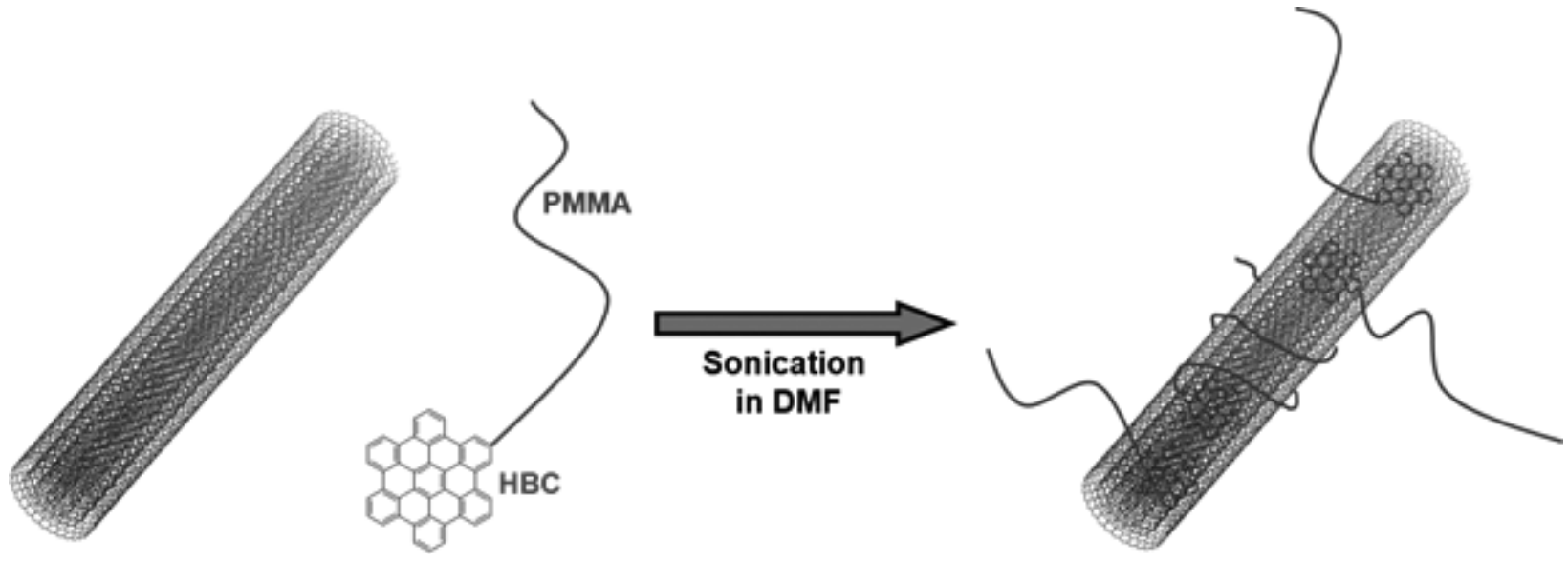

Figure 1. Schematic representation of HBC-PMMA-grafted MWCNT. 

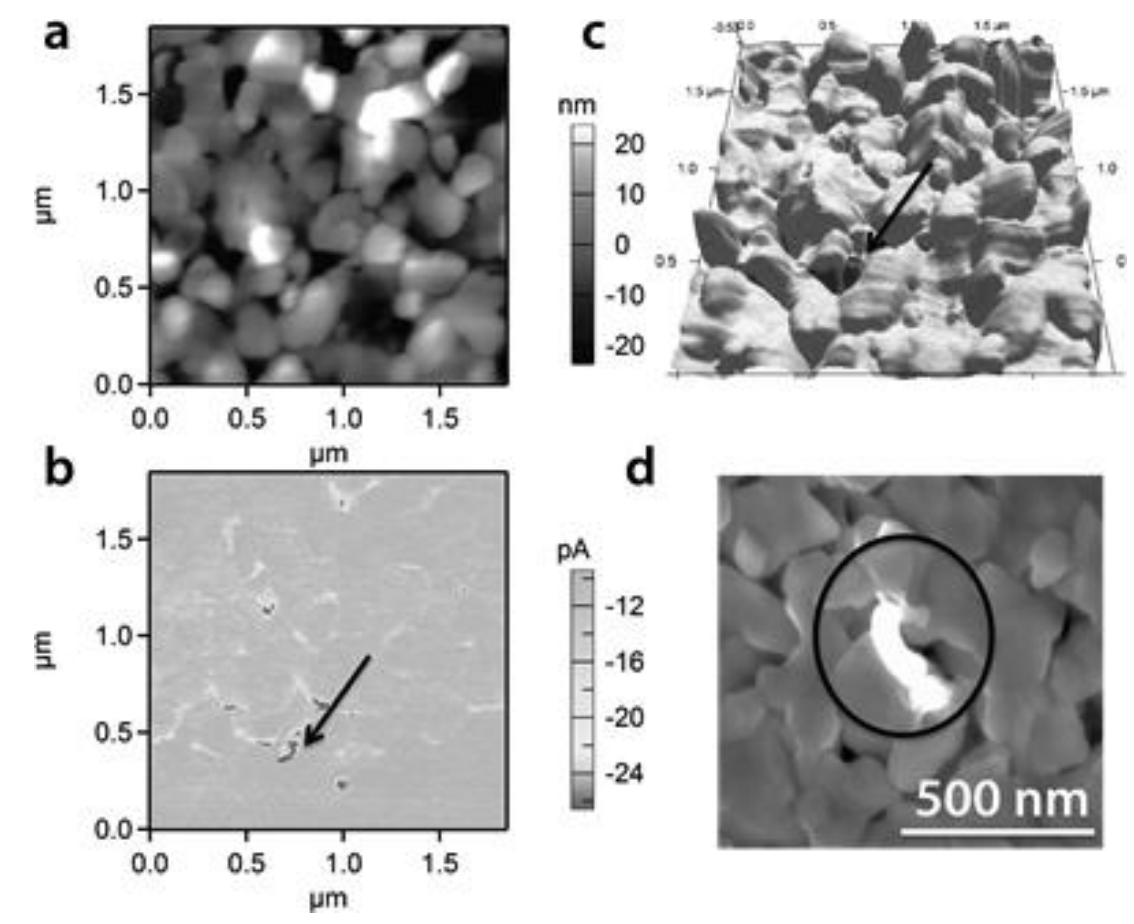

Figure 2. (a) AFM topographic image of $\mathrm{PbI}_{2} / \mathrm{MWCNT}$ composite film on PEDOT:PSS-coated ITO substrate. (b) cAFM image of the same area. (c) Topographic image superimposed onto current mapping from cAFM. High current regions are from MWCNTs. (d) SEM image of $\mathrm{PbI}_{2} / \mathrm{MWCNT}$ composite film on Si substrate. A MWCNT is highlighted with a circle. 

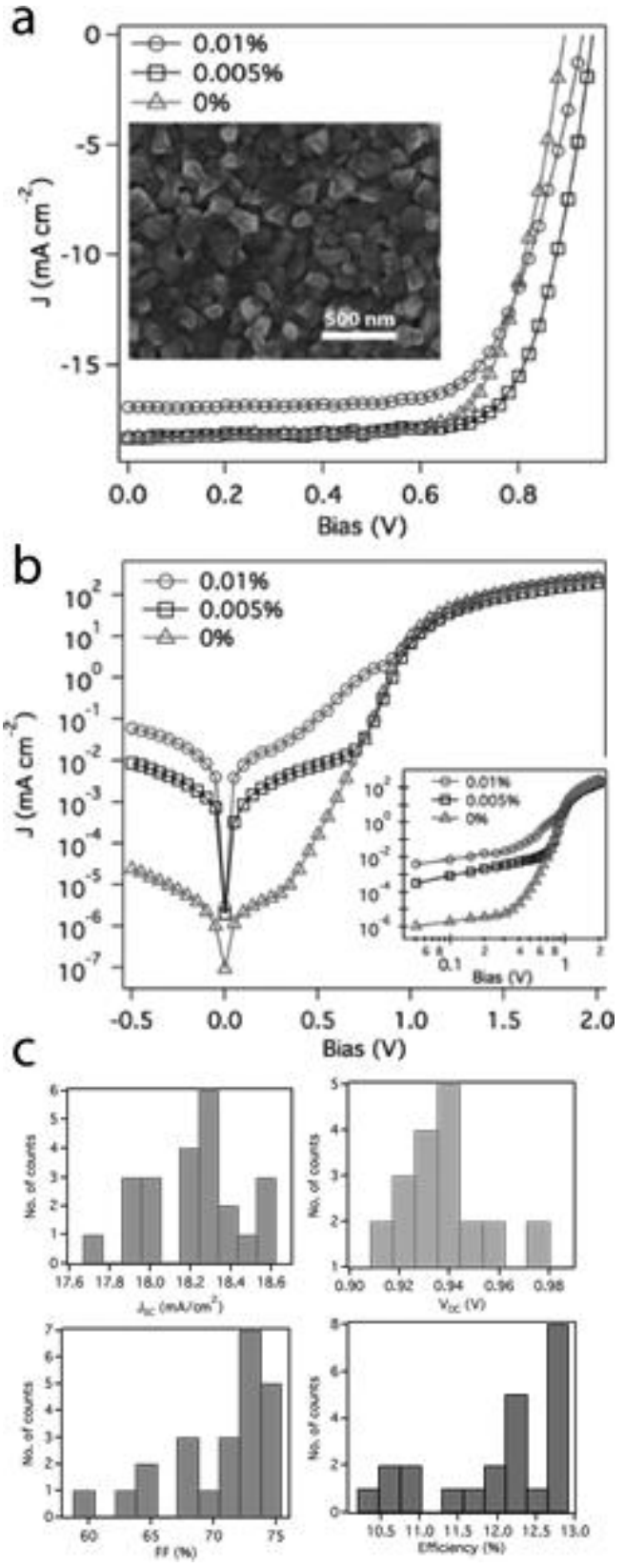

Figure 3. (a) J-V curves from steady exposure to light of three lead tri-iodide-based perovskite photovoltaic devices with active layers containing $0 \%, 0.005 \%$ and $0.01 \%$ MWCNTs (by wt. to $\mathrm{PbI}_{2}$ ) averaged over 9 samples from different substrates of the same batch of experiments. Inset: Top SEM image of perovskite sample containing no CNTs. (b) Dark J-V characteristics of perovskite photovoltaic devices with active layers containing $0 \%$ (triangles), $0.005 \%$ (squares) and $0.01 \%$ (circles) of MWCNTs. The inset shows a log-log plot of the dark J-V curves. (c) Device performance histograms for 22 devices containing $0.005 \%$ MWCNT. 

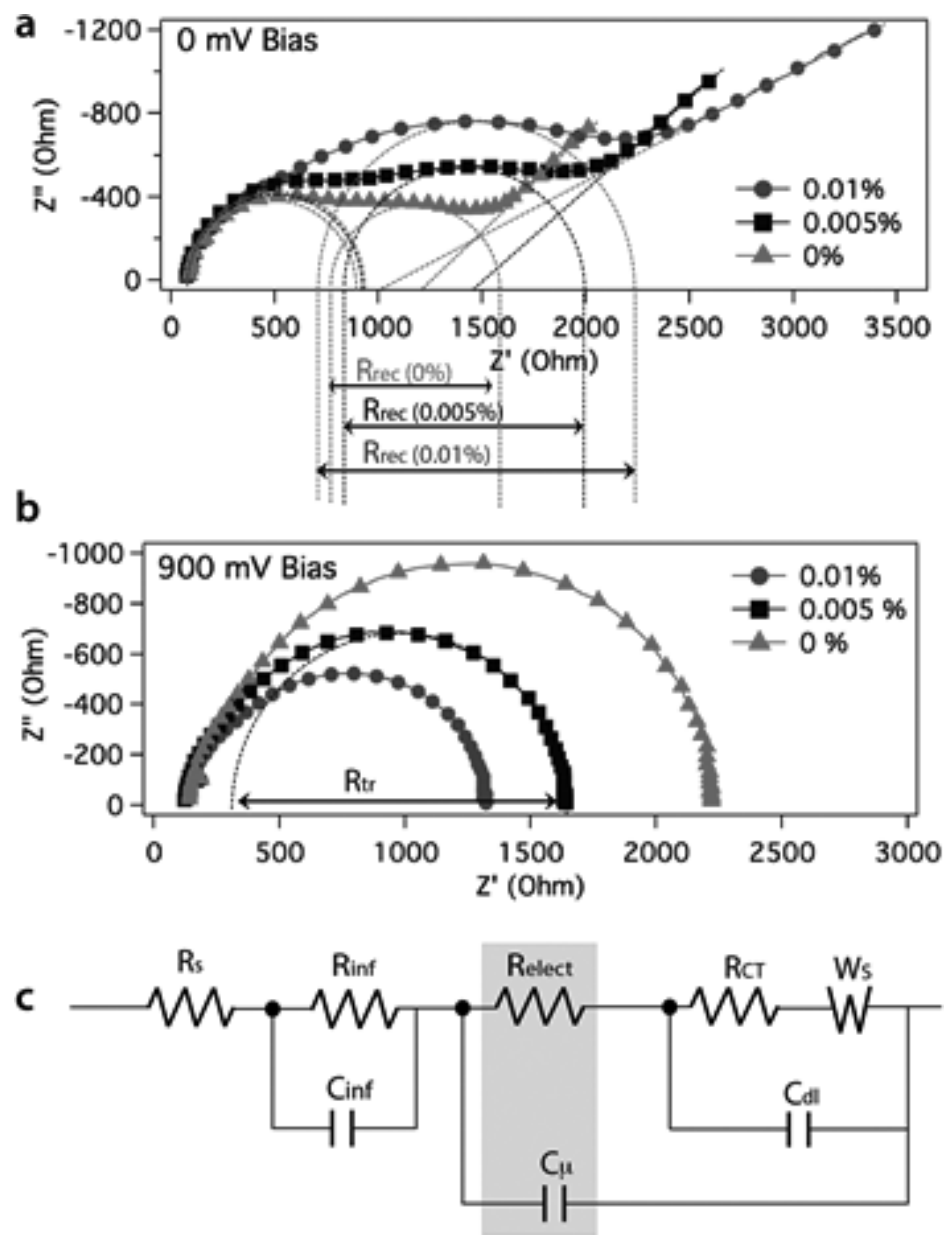

Figure 4. EIS plot of perovskite solar cells under AM1.5G solar simulator at $100 \mathrm{~mW} \cdot \mathrm{cm}^{-2}$ light intensity at a bias voltage of (a) $0 \mathrm{~V}$ and (b) $900 \mathrm{mV}$. The frequency range is from $100 \mathrm{~Hz}$ to $1 \mathrm{MHz}$ at $20 \mathrm{mV}$ AC amplitude. (c) Equivalent circuit diagram for the perovskite solar cell. $\mathrm{R}_{\text {elect }}$ represents the electronic transport component and $\mathrm{W}_{\mathrm{S}}$ represents the Warburg diffusion element. The shaded area represents the intermediate-frequency component of the Nyquist plot. 


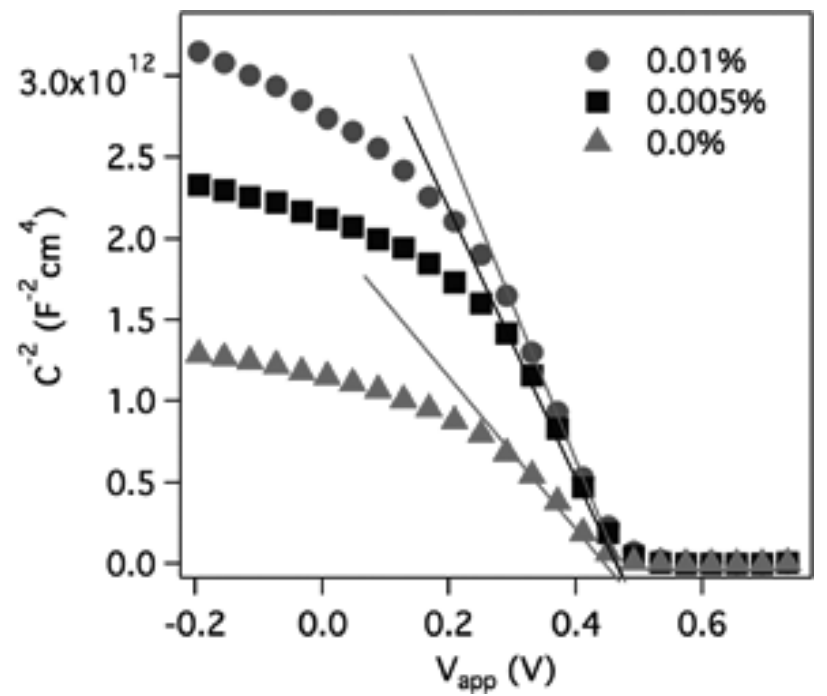

Figure 5. Mott-Schottky plot of lead tri-halide perovskite solar cells containing MWCNTs at concentrations of $0 \%$, $0.005 \%$ and $0.01 \%$ (by wt. to $\mathrm{PbI}_{2}$ ) in the bulk of the perovskite films at $100 \mathrm{~mW} \cdot \mathrm{cm}^{-2}$ light intensity. Capacitance was measured at a $10 \mathrm{kHz}$ oscillation frequency with $20 \mathrm{mV}$ AC amplitude. 


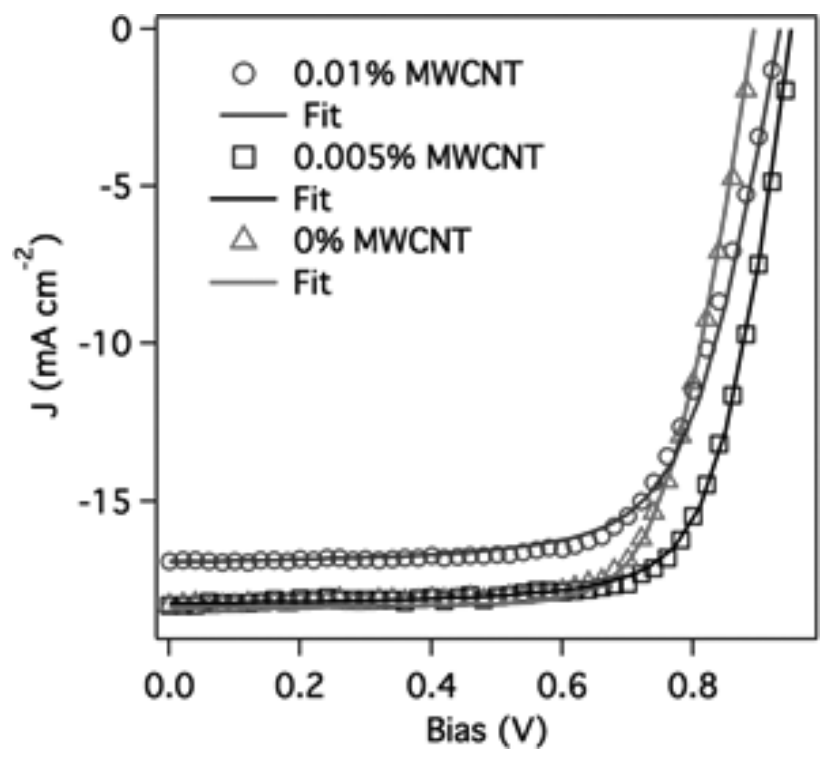

Figure 6. (a) Best fitting of simulation predictions according to the drift-diffusion-reaction model (solid lines) to the experimentally measured $\mathrm{J}-\mathrm{V}$ characteristics (open symbols) in perovskite photovoltaic devices for $0 \%, 0.005 \%$ and $0.01 \%$ (by wt. to $\mathrm{PbI}_{2}$ ) concentration of MWCNTs in the active layer. 


\section{Graphical Abstract}

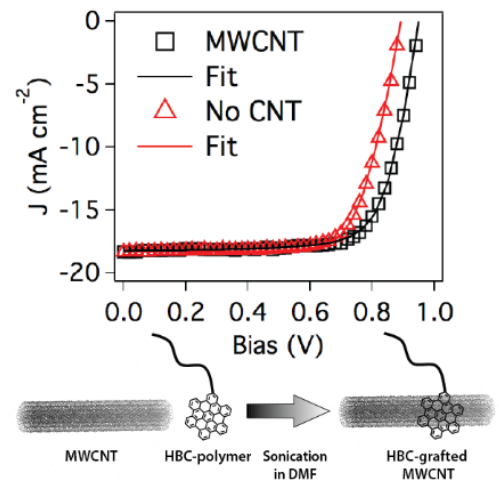

